\section{Echolocation in the blinded rat}

\author{
RUSSELL A. BELL, M. E. NOBLE, and W. F. DAVES* \\ Kansas State University, Manhattan, Kansas $66502 \dagger$
}

The difference threshold for detection of barriers at different distances using a modified method of limits was found, for four blinded rats, to be 9 in. White noise $20 \mathrm{~dB}$ above ambient level reduced discrimination performance to chance, indicating that auditory cues were involved in the discrimination. A second determination, utilizing the method of constant stimuli, confirmed the difference threshold to be $9 \mathrm{in}$. and reduced individual $\mathrm{S}$ variation by further training. Evidence with a black and a white barrier indicated the possibility that infrared heat cues do not enter into the discrimination.

The location of stimulus objects by means of reflected sounds (echolocation) is a relatively recently discovered sensory mode and has generated much interest because of its unusual nature. The phenomenon seems to be a primary sensory mode in animals such as the bat and the porpoise, who employ ultrasonic echo ranging in their search for food and in the avoidance of obstacles (Galambos \& Griffin, 1942; Griffin, 1950; Kellogg \& Kohler, 1952; Kellogg, Kohler, \& Morris, 1953; Kellogg, 1959). However, other animals have recently been shown to exhibit this sensory ability as a secondary sensory mode. There is quantitative evidence that blind human beings are able to detect the presence of obstacles by means of auditory cues (Supa, Cotzin, \& Dallenbach, 1944; Cooper, 1950; Kellogg, 1962; Rice \& Feinstein, 1965; and Rice, 1967), thus indicating that ultrasonic capabilities are not necessary for echolocation. Also, Griffin (1953) has shown that the bird, Steatornis, apparently uses low-frequency sounds in echolocation.

The laboratory rat seems to possess some of the same characteristics for receiving auditory cues as the bat and the porpoise (Gould \& Morgan, 1941; Anderson, 1954), and recent work with blinded rats has shown that they are able to detect obstacles by means of self-produced auditory cues (Riley \& Rosenzweig, 1957; Dashiell, 1959). In the latter study, incidental evidence suggested echolocation when it was discovered that neither sighted nor blinded animals showed disorientation in a maze when new interrupting walls were installed.

Further understanding of the

* $R$. A. Bell is now at the Marketing Research Section, E. I. du Pont de Nemours \& Company, Inc., Wilmington, Delaware; M. E. Noble is now at Pennsylvania State University; and W. F. Daves is now at Georgia State College. The authors are indebted to Harry Helson for his advice in the design of the experiment.

tThis manuscript was prepared at the Human Engineering Laboratories, Aberdeen Research and Development Center, Aberdeen Proving Ground, Maryland. echolocation phenomenon will partly pointing up the limits of the capacity in various species and also similarities and differences between echolocation and other sensory processes. The present experiments are an attempt to quantify the capacity of the blinded echolocation. The difference threshold (DL) for the discrimination of barrier distance is determined by using the method of limits (Experiment 1) and the method of constant stimulus difference (Experiment 2). Also, the design of Experiment 1 includes a random noise masking condition in order to provide corroborative evidence of the auditory basis of the discrimination. In Experiment 2, one condition employs black and white barriers in order to explore the possible role of infrared heat cues in the discrimination.

\section{EXPERIMENT 1}

Method

Subjects. Ss $(\mathrm{N}=4$ littermates; 2 males and 2 females) were pigmented rats of the Long-Evans strain. They were blinded by enucleation at 15 days of age and were weaned at 25 days of age. A 22-h food-deprivation schedule was begun at 36 days of age, and training was begun at 50 days of age. The deprivation schedule was maintained throughout the experiment.

Apparatus. The Ss were trained and tested on a two-choice elevated maze patterned after that used by Rosenzweig, Krech, \& Riley (1955). Runways, 2 in. wide and 29.5 in. long, formed a square, with the start- and goalboxes located on opposite corners. The startbox was separated from each runway by a .5-in. gap. A wooden barrier, 6 in. square, was suspended over each runway by means of a floor stand. Thus, the barrier did not contact the runway. The distance of the barrier from the choice point could be varied, and each barrier could be raised or lowered, thus allowing $S$ passage along the runway or blocking it. The walls of the test chamber were depend upon quantitative experiments rat to discriminate barriers by lined with egg cartons to absorb extraneous sound. Sound levels were measured by a General Radio Company sound-level meter.

Procedure. On each trial, S was released from the startbox and allowed to choose one of the runways. A choice was scored incorrect if $\mathbf{S}$ placed all four feet on the incorrect runway. Following each incorrect choice, $\mathrm{S}$ was picked up and returned to the startbox. Following each correct choice, $S$ was allowed to run to the goalbox and to eat for $15 \mathrm{sec}$ before being picked up and returned to the startbox. The intertrial interval was 45-60 sec. Whenever it was necessary to move a barrier, both were moved in order to control for auditory cues. During all phases of experimentation, the incorrect runway was blocked by a barrier placed 8.5 in. from the choice point. Each $S$ received 20 trials per day, with the position (right or left) of the negative barrier being determined by one of three 20-trial Gellerman sequences. The particular sequence employed on any one day was selected at random. The experiment was divided into the three following phases.

In the first phase, Ss were trained to choose the open runway (i.e., to detect and avoid the barrier). The criterion for proceeding to the next phase was an average of $85 \%$ correct choices for 5 consecutive days, with performance on no one day falling below $80 \%$ correct choices.

In the second phase, the difference thresholds were determined. A barrier was introduced over the positive runway at $29.5 \mathrm{in}$. from the choice point and moved 3 in. closer each day until performance approached the chance level (50\%). Immediately after each correct choice (all four feet in the correct alley), $\mathbf{E}$ raised the barrier to allow $\mathrm{S}$ to run to the goalbox. The DL was defined as the difference in distance at which $75 \%$ of the trials were correct.

In the third phase, all Ss were first placed for 7 days in a room with continuous random noise, $20 \mathrm{~dB}$ above ambient level. This was done in order to minimize any disturbing effects of the initial introduction of noise in the test situation. They were then retrained to criterion. Next, a loudspeaker was placed in the center of the maze and random noise was directed at the choice point, with the negative barrier at 8.5 in. from the choice point. The noise was introduced at $5 \mathrm{~dB}$ above ambient level and increased $5 \mathrm{~dB}$ each day until performance approached chance level. The Ss were then retested without the noise.

Results

Figure 1 indicates the mean 


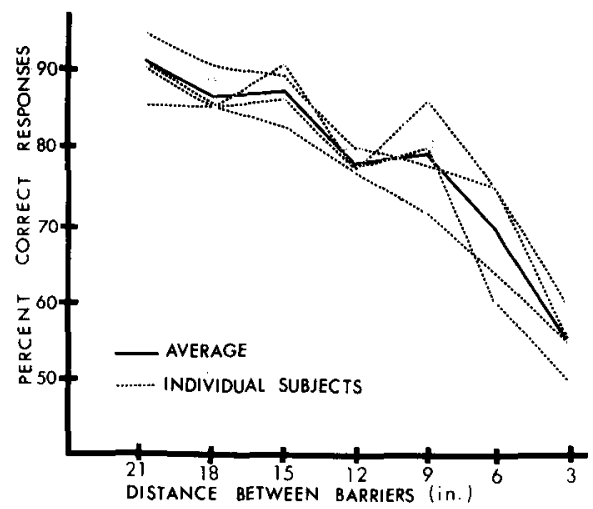

Fig. 1. Mean performance for individuals and for all rats combined as a function of distance between positive and negative barriers.

performance both for individuals and for all Ss combined as a function of difference in distance between positive and negative barriers. The average $\mathrm{DL}$ was 9 in., with individual DLs varying between 6 and $12 \mathrm{in}$. Two inversions are seen in the generally monotonic curves. One $S$ showed better performance at 15 than at 18 in., and two Ss were better at 9 than at 12 in. They are discussed below.

Performance under the noise condition is indicated in Fig. 2. Noise $20 \mathrm{~dB}$ above ambient level was sufficient to reduce performance to approximately chance level (performance $<70 \%$ is nonsignificant for $\alpha=.05$ ). When retested under ambient noise, however, performance returned to that of prenoise levels.

\section{EXPERIMENT 2}

The shape of the psychophysical function found in Experiment 1 is not that customarily found in psychophysical experimentation, in that the curve does not drop as sharply as the usual ogive. Also, the inversions mentioned above, while perhaps due to chance, might not be expected in a careful psychophysical determination. It is possible that the method of quantification employed in Experiment 1 which used only descending trials of differential distances, could have resulted in some procedural artifact. The inversions in performance may have occurred when the Ss first detected the second barrier, i.e., when the task in effect changed from one barrier detection to barrier discrimination. Improvement in the latter task would then account for the upswing at the next distance. It is conceivable, then, that further training at the shorter distances would have resulted in improved performance at the new task. Experiment 2 was designed to explore these possibilities.

\section{Method}

Subjects. The $\mathrm{Ss}(\mathrm{N}=7)$ were male albino rats of the Sprague-Dawley strain obtained from Dan Rolfsmeyer \& Son, Madison, Wisconsin. They were blinded by enucleation at 60 days of age. A 22-h food-deprivation schedule was begun at 156 days of age, and training was begun at 170 days of age. This schedule was maintained throughout the experiment.

Apparatus. The Ss were trained and tested on a two-choice elevated Y-maze. Runways were 2 in. wide and 29.5 in. long, with identical goalboxes at each end. The starting platform was separated from each runway by a .5-in. gap. The 6-in.-square barrier was suspended and operated as described in Experiment 1. The modifications of goalboxes and starting apparatus were made to allow $E$ to remain in a stationary position during the experimental session and thus reduce the possibility of additional cues. The change from a startbox to a platform also was designed to cause the animals to make more attempts to run the maze early in training. The walls and ceiling of the test chamber were lined with egg cartons and the floor was carpeted to minimize extraneous sounds.

Procedure. On each trial, $\mathbf{S}$ was placed on the starting platform and allowed to move onto one of the runways. A choice was scored as incorrect when both feet were placed on the incorrect runway. Following each incorrect choice $\mathbf{S}$ was removed from the maze. Following each correct choice $S$ was allowed to run to the goalbox and to consume three $50-\mathrm{mg}$ Noyes standard Skinner box reward pellets. The animal,was then removed from the maze, and the barriers were set for the next trial. Whenever it was necessary to move a barrier, both were moved in order to control for auditory cues. The goalboxes contained equal amounts of food at all times to eliminate olfactory cues. The intertrial interval was 50-75 sec. During all phases of the experiment, the incorrect runway was blocked by a barrier $8.5 \mathrm{in}$. from the choice point. The position (right or left) of the negative barrier was determined by one of four 10-trial Gellerman sequences, each of which was presented every fourth day. The experiment was divided into four phases.

In the first phase, training to choose the open runway was identical to the first phase of Experiment 1.

In the second phase, a second barrier was introduced over the positive runway at $20.5 \mathrm{in}$. from the choice point, and $\mathrm{Ss}$ were given 5 consecutive days of training at this

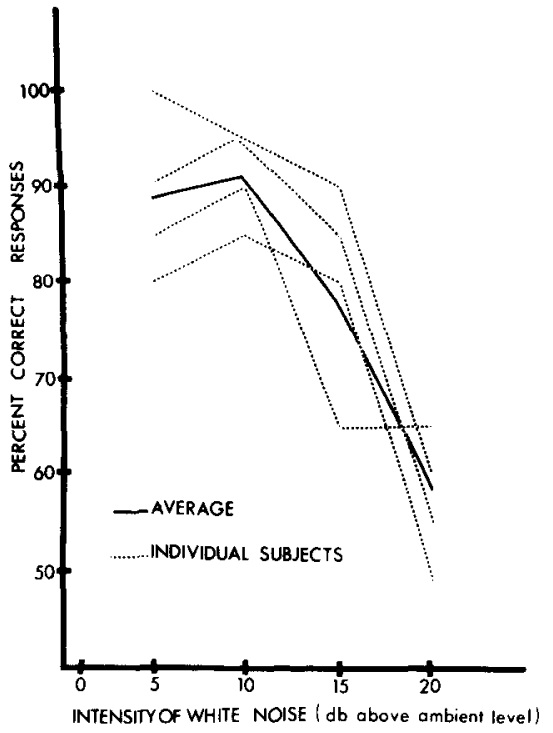

Fig. 2. Mean performance for individuals and for all rats combined as a function of white-noise intensity.

task.

Third, the difference threshold was determined by the method of constant stimulus differences over a 12-dav period. The four correct positions of $20.5,17.5,14.5$, and 11.5 in. were presented randomly five times on each of 12 days for a total of 60 trials per barrier position. After each correct choice, $E$ raised the barrier to allow the rat to reach the goalbox. The DL was defined as that point at which the rat was correct on $75 \%$ of the trials.

In the fourth phase, a black or a white barrier was placed 17.5 in. from the choice point. Thus, each $S$ had a choice between a gray bárrier and either a black or a white barrier, depending on the particular trial sequence. Each animal received 20 trials per day for 2 consecutive days to test for the possibility of the utilization of infrared heat cues.

Results

The principle results of Experiment 2 are given in Fig. 3, which shows the mean performance for individuals and for all Ss combined as a function of difference in distance between positive and negative barriers. The average $\mathrm{DL}$ was $9.6 \mathrm{in}$., with individual DLs varying from 9 to 9.9 in.

In the infrared phase of the experiment, the nongray barriers were selected $49.3 \%$ of the time. Of the nongray preferred trials, $50.1 \%$ of the choices were to the black barrier, strongly suggesting that use of infrared heat cues cannot account for the results of this experiment.

\section{DISCUSSION}

It now seems rather certain that 


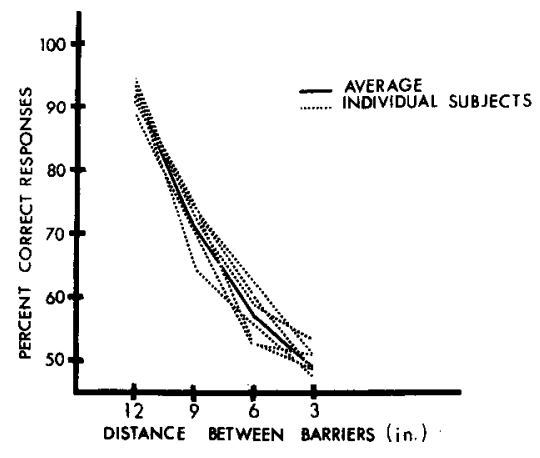

Fig. 3. Mean performance for individuals and for all rats combined as a function of distance between positive and negative barriers for Experiment 2.

obstacle discrimination in the blinded rat is based on auditory cues. The evidence of Riley and Rosenzweig (1957) and Dashiell (1959) indicates that this discrimination is auditory and based on self-produced cues. The decrement in performance under the white noise condition of Experiment 1 also indicates that the Ss were indeed using auditory cues in detecting and discriminating the barriers. However, there is still no evidence leading to a precise specification of these cues. The Ss produced a variety of sounds audible to the $E$, any of which might have been utilized in the discrimination; $E$, of course, would not have detected high-frequency sounds potentially detectable by $S$.

The present experiments have added quantitative evidence concerning the unusual sensory mode of echolocation in blinded rats. In two experiments with an 8.5-in. barrier, the DL was found to be approximately $9 \mathrm{in}$. giving a Weber fraction of approximately 1.0 .

Additional quantitative evidence on the abilities of various species may provide important clues as to the nature of the physical properties of the auditory cues in the echolocation phenomenon. Kellogg (1962) has shown that size discrimination is possible in the blind human being and reports a threshold fraction ratio of about 1/4. Rice and Feinstein (1965) and Rice, Feinstein, \& Shusterman (1965) report that this ratio of the size of the threshold target to the standard was relatively constant, regardless of the distance.

\section{REFERENCES}

ANDERSON, J. W. The production of ultrasonic sounds by laboratory rats and other mammals. Science, 1954, 119, 808 .

COOPER, F. S. Guidance devices for the blind. Phy sics Today, 1950, 3, 6-14.

DASHIELL. J. F. The role of vision in spatial orientation by the white rat Journal of Comparative \& Physiological Psychology, 1959, 50, 522-526.

GALAMBOS, R., \& GRIFFIN, D. R. Obstacle avoidance by flying bats: The cries of bats. Journal of Experimental Zoology, 1942, 89, 475-490.

GOULD, J. \& MORGAN, C. Hearing in the rat at high frequencies. Science, 1941, 94, 168.

GRIFFIN, D. R. Measurements of the ultrasonic cues of bats. Journal of the Acoustical Society of America, 1950, 22, 247-255.

GRIFFIN, D. R. Acoustic orientation in the Oil Bird, Steatornis. Proceedings of the National Academy of Science, 1953, 39, 884-893.

KELLOGG, W. N. Auditory perception of submerged objects by porpoises. Journal of the Acoustical Society of America, $1959,31,1-6$.

KELLOGG, W. N. Sonar system of the blind. Science, 1962, 137, 399-404.

KELLOGG, W. N., \& KOHLER, R. Reactions of the porpoise to ultrasonic frequencies. Science, 1952, 116, 250-252.

KELLOGG, W. N., KOHLER, R., \& MORRIS, H. N. Porpoise sounds as sonar signals. Science, 1953, 117, 239-243.

RICE, C. E. Human echo perception. Science, 1967, 155, 656-664.

RICE, C. E., \& FEINSTEIN, S. H. Sonar system of the blind: Size discrimination. Science, 1965, 148, 1107-1108.

RICE C. E. FEINSTEIN, S. H. \& SHUSTERMAN, J. Echodetection ability of the blind: Size and distance factors. Journal of Experimental Psychology, 1965, 70, 246-251.

RILEY, D. A., \& ROSENZWEIG, M. R. Echolocation in rats. Journal of Comparative \& Physiological Psychology, $1957,50,323$.

ROSENZWEIG, M. R., KRECH, D., \& RILEY, D. A. Evidence for echolocation in the rat. Science, $1955,121,600$.

SUPA, M. COTZIN, M., \& DALLENBACH $K$. M. Facial vision: The perception of obstacles by the blind. American Journal of Psychology, 1944, 57, 133-147.

(Accepted for publication March 5, 1971.) 